Research Paper

\title{
Hemodynamic Reactivity to Laboratory Stressors in Healthy Subjects: Influence of Gender and Family His- tory of Cardiovascular Diseases
}

Giovana M. S. Simoes ${ }^{1}$, Bianca P. Campagnaro ${ }^{2}$, Clarissa L. Tonini², Silvana S. Meyrelles², Fatima H. Sert

Kuniyoshi ${ }^{3}$, Elisardo C. Vasquez ${ }^{1,2, \bigotimes}$

1. Emescam College of Health Sciences, Vitoria, ES, Brazil;

2. Department of Physiological Sciences, Health Sciences Center, Federal University of Espirito Santo, Vitoria, ES, Brazil;

3. Division of Cardiovascular Diseases, Department of Internal Medicine, Mayo Clinic and Foundation, Rochester, MN, USA.

$\square$ Corresponding author: Elisardo C Vasquez, PhD. Department of Physiological Sciences, Health Sciences Center, Federal University of Espirito Santo, Av. Marechal Campos 1468, Vitoria, ES 29043-900, Brazil. Phone (55-27) 3335-7334, Fax (55-27) 3335-7330 Email: evasquez@pq.cnpq.br.

() Ivyspring International Publisher. This is an open-access article distributed under the terms of the Creative Commons License (http://creativecommons.org/ licenses/by-nc-nd/3.0/). Reproduction is permitted for personal, noncommercial use, provided that the article is in whole, unmodified, and properly cited.

Received: 2013.01.27; Accepted: 2013.05.05; Published: 2013.05.08

\begin{abstract}
Although laboratory stressor tests have been applied as a preliminary protocol in some cardiovascular studies, there is a lack of data comparing the pressor and chronotropic responses among the main stressor tests. Therefore, the aim of this study was to evaluate the variability in hemodynamic responsiveness to the main stressor tests, establish a hyperresponsiveness cutoff criterion and analyze the influence of gender and family history of cardiovascular diseases (CVDs) in healthy subjects. We examined hemodynamic responses to physical (cold pressor and handgrip tests) and mental (Stroop color-word test) stressors in 98 subjects (48 males and 50 females) without CVDs. All stressor tests resulted in increased blood pressure (BP) levels, which were lower and less dispersed in the handgrip test compared to the cold pressor test. Adopting the $75^{\text {th }}$ percentile as the cutoff in our data, we classified subjects exhibiting absolute pressor changes equal to or higher than 14,24 and $36 \mathrm{mmHg}$ in systolic and 9, I3 and $24 \mathrm{mmHg}$ in diastolic BP during the handgrip, Stroop and cold pressor test, respectively, as hyperresponsives. Males exhibited greater $(\mathrm{p}<0.05)$ increases in systolic BP in the handgrip ( $11 \%$ vs. $8 \%$ ) and cold pressor $(25 \%$ vs. $21 \%)$ tests and in diastolic BP in the handgrip (12\% vs. $7 \%$ ) and Stroop (22\% vs. $19 \%)$ tests than females. A positive association between family history of CVDs and pressor hyperreactivity to stressor tests was observed. We propose using the $75^{\text {th }}$ percentile of hemodynamic sample values as a cutoff criterion to classify individuals as pressor or chronotropic hyperreactives. We conclude that hemodynamic responsiveness to stressor tests in healthy subjects is positively influenced by male gender and family history of CVDs.
\end{abstract}

Key words: stressor test; handgrip test; Stroop test; Cold pressor test; blood pressure; heart rate.

\section{Introduction}

Laboratory stressor tests have been used as a research strategy to examine the cardiovascular reactivity in normotensive and hypertensive subjects [1-3]. Recently, Carroll et al. [4] have examined the hemodynamic reactions to psychological stress and observed that individuals exhibiting exaggerated blood pressure $(\mathrm{BP})$ reactivity were at increased risk of subsequently dying from cardiovascular disease.

The laboratorial stressor tests can be divided into two main categories. One involves the emotional aspect of the individual, e.g., the mental arithmetic stress test [4] and the conflict color-word test, devel- 
oped by Stroop [5], which has been used to test pressor and chronotropic responsiveness in diverse cardiovascular diseases [6,7]. The second includes stressors that promote physical stimuli, e.g., the isometric handgrip test $[6,8]$ and the cold pressor test $[1,9]$. The laboratory stressors have also been divided into passive coping stressors (e.g., the cold pressor test) and active coping stressors (e.g., Stroop test) based on the tasks of the subjects [10].

It is well known that laboratory stressors cause an increase in BP and heart rate (HR) and that the hemodynamic responses are greater in individuals with cardiovascular diseases than in healthy subjects $[2,11,12]$. However, there is a lack of criteria to classify hyperreactivity to stressor tests.

Hemodynamic reactivity to psychological and physical stressors has been tested in health subjects $[2,3,13-16]$ and in different disease conditions, such as atherosclerosis [6,17], obesity [11] and as a tool to predict future cardiovascular risk [4,18-25]. The cardiovascular reactivity to stressor stimuli has been extensively reviewed [26-28] in meta-analyses. The association of family history of cardiovascular diseases with cardiovascular responses to stress has also been investigated $[14,25,26]$. Despite all literature, there is a need of more studies about the variability in hemodynamic to stressor tests in healthy humans, comparison of traditional stressor tests, and how they are influenced by gender and family history of cardiovascular diseases. Therefore, the aim of the present study was to evaluate the pressor and chronotropic responsiveness to mental and physical stressors in normotensive subjects. We examined the hypothesis that the pressor and chronotropic responsiveness to stressors is influenced by gender and family history of cardiovascular diseases.

\section{Research Methods and Procedures}

\section{Study population}

We recruited 98 volunteers (50 females and 48 males) from members of the academic staff and students at the two major schools of health sciences in Vitoria, Brazil, who previously reported being in good health. Participants were excluded if they were obese, had a history of autonomic dysfunction, cardiovascular disease, or diabetes or if they were smokers. The study was approved by the Human Subject Protection Committee at the Biomedical Center of the Federal University of Espirito Santo; all participants signed an informed and written consent form. No inducement was offered to participants for taking part in the study.

\section{Biochemical measurements}

Fasting blood samples were obtained for biochemical analyses of glycemia and the lipid profile. Diabetes was defined as fasting blood glucose level $\geq$ $126 \mathrm{mg} / \mathrm{dl}(7.0 \mathrm{mmol} / \mathrm{L})$ or previously diagnosed type 2 diabetes mellitus. Obesity was defined based on body mass index (BMI) $>30 \mathrm{~kg} / \mathrm{m}^{2}$. Dyslipidemia was defined as triglycerides $\geq 200 \mathrm{mg} / \mathrm{dL}$ (2.3 $\mathrm{mmol} / \mathrm{L}), \mathrm{HDL}<40 \mathrm{mg} / \mathrm{dL}(1.04 \mathrm{mmol} / \mathrm{L})$ and LDL $>130 \mathrm{mg} / \mathrm{dL}$ (3.37 mmol/L) or specific treatment for this lipid abnormality.

\section{Blood pressure and heart rate measurements}

$\mathrm{BP}$ and HR were measured using an automated sphygmomanometer device (Omron, model HEM-705CP, Omron Healthcare Inc., USA). The blood pressure cuff was placed around the non-dominant upper arm because the dominant arm was left free to perform maneuvers necessary to perform the stressor tests. Three baseline BP readings were taken at 2-min intervals by one of the investigators dressed in a white coat to simulate clinical readings. An average of the 3 measurements was used as the basal value for subsequent analysis. Arterial hypertension was defined as systolic pressure $\geq 140$ $\mathrm{mmHg}$ and/or diastolic pressure $\geq 90 \mathrm{mmHg}$ or specific treatment for hypertension.

\section{Isometric handgrip test}

The purpose of this experiment was to determine the magnitude of the change in blood pressure and heart rate control during the activation of central command, mechanoreceptor, and metaboreceptor controls. The handgrip exercise was performed with the dominant arm at 30\% maximal voluntary contraction (MVC) for $3 \mathrm{~min}$. Participants were instructed to breathe normally during the test and avoid the inadvertent performance of a Valsalva maneuver. BP and HR were measured every min immediately before the test for $3 \mathrm{~min}$ (baseline) and every min during the test and the posttest period until the baseline values were recovered.

\section{Stroop word-color conflict test}

The Stroop test [5] was used to assess attentional flexibility by testing individuals' accuracy and speed (latency) in responding to a set of colored words, in which the colors of the word either corresponded to the meaning of the word or not. For example, the word "green" may be colored green (congruent), in which case the correct response is green. However, if the word "green" is colored blue (incongruent), requiring the individual to inhibit his/her automatic tendency to read the word, the individual must re- 
spond by naming the color of the word (blue), not the meaning of the word. In total, four colors (red, blue, yellow and green) were used in the modified version of the Stroop Test. The participants were urged to proceed as rapidly as possible and were gently chastised for incorrect responses. They were asked to try their best, but the number of correct answers was not quantified. BP and HR were measured every min immediately before the test (baseline) and every min during the test and posttest until the baseline values were recovered.

\section{Cold pressor test}

The purpose of this test was to study the impact of prolonged sensorial stimuli by the cold pressor test on BP and HR. The participants were required to immerse their open hand up to the wrist in a bucket containing a 12-cm-deep mixture of ice and water (averaging $4{ }^{\circ} \mathrm{C}$ ). To ensure a constant temperature throughout every experiment and similar conditions for all subjects, an automated device was used. They were asked to remain in this condition for $2 \mathrm{~min}$, but were not informed beforehand about the test time or water temperature. The participants could withdraw their hand from the water if the pain became unbearable, but in this case, data were not considered in the study. BP and HR were measured every min immediately before the test (baseline) and every min during the test and the posttest until the baseline values were recovered.

\section{Experimental protocol}

The participants underwent an initial evaluation, consisting of direct questions regarding lifestyle habits, such as smoking, alcohol use, physical activity, and habitual use of drugs, and family history of cardiovascular disease (arterial hypertension, myocardial infarction and/or stroke). Participants who met the inclusion criteria were scheduled for fasting blood samples collection to assess the levels of glucose, total cholesterol, HDL, and triglycerides. Participants who met the inclusion criteria then returned to the lab, and anthropometric, BP and HR measurements were obtained. The pressor and chronotropic responses to the 3 stress tests described above were evaluated in the final visit. Given that cardiovascular reactivity to acute stressors can be influenced by circadian variations in BP and HR, the laboratory stress tests were applied in the morning from 08:00 to 10:00 $\mathrm{h}$ for all cases.

\section{Statistical analysis}

BP and HR measurements were obtained before the test and every min for 4 min during the test and the recovery period. Because the pressor and chronotropic responses in each of the three tests were maximal at different times points, we selected the time of the greatest magnitude of the response; the $3^{\text {rd }} \min$ for the handgrip test, the $4^{\text {th }}$ min for the Stroop test and the $2^{\text {nd }}$ min for the cold pressor test. The BP and HR responses during the tests were compared to the baseline measurements.

The data are summarized as means \pm SD or SEM or the median depending on data distribution. The normality (Gaussian distribution) of the variables was analyzed using the D'Agostino and Pearson omnibus test. When this test was significant, unpaired Student's $t$ test was used to compare means between males and females. When the test of normality was not significant, statistical analysis was performed using the nonparametric Kruskal-Wallis test followed by Dunn's post hoc test to compare pairs of groups. Two-way ANOVA for repeated measures was used to compare the time (basal, test and recovery) and gender effects on changes in BP and HR during the stressor tests; partial eta-squared $\left(\eta^{2}\right)$ was used as a measure of effect size. Statistical analysis was performed using the GraphPad Prism program (version 6.0, GraphPad Software, San Diego, CA, USA) and the SPSS software (version 18.0, IBM, Armonk, NY, USA). Power analysis was performed using the $G^{*}$ Power 3.1 software (freeware, review: [29]). Two-tail $p$ values $\leq$ 0.05 were considered significant.

\section{Results}

\section{Sample characteristics}

Of the 98 participants enrolled in this study, 49\% were men, at the mean age was $27 \pm 6$ years, and the mean BMI was $22 \pm 2 \mathrm{~kg} / \mathrm{m}^{2}$.

Twenty-seven percent of the participants reported family history of cardiovascular diseases. A comparison of the characteristics of participants by gender is shown in Table 1. Males and females had similar characteristics, except that the prevalence of family history of cardiovascular diseases was higher in men $(55 \%$ vs. $25 \%, \mathrm{p}<0.01)$, and blood pressure levels were also higher in men.

The average casual resting systolic and diastolic $\mathrm{BP}$ of the sample was $119 \pm 3.6$ and $71 \pm 2.8 \mathrm{mmHg}$, respectively. Males showed significantly higher levels $(119 \pm 3.3$ and $73 \pm 2.6 \mathrm{mmHg}$, respectively) than females $(104 \pm 3.0$ and $68 \pm 2.6 \mathrm{mmHg}$, respectively, $p<0.05)$. The casual resting HR value of the sample was $76 \pm 3.3 \mathrm{bpm}$; however, unlike $\mathrm{BP}$, there was no significant difference between females and males ( $77 \pm 3.5$ vs. $75 \pm 3.3 \mathrm{bpm}$, respectively). 
Table I. Characteristics of the sample.

\begin{tabular}{|c|c|c|c|}
\hline \multirow[t]{2}{*}{ Parameters } & \multicolumn{3}{|l|}{ Gender } \\
\hline & $\begin{array}{l}\text { Female } \\
(50)\end{array}$ & $\begin{array}{l}\text { Male } \\
(48)\end{array}$ & $\begin{array}{l}\text { Total } \\
(98)\end{array}$ \\
\hline Age (years) & $27 \pm 7$ & $26 \pm 4$ & $27 \pm 6$ \\
\hline Body mass index $\left(\mathrm{kg} / \mathrm{m}^{2}\right)$ & $21 \pm 2$ & $23 \pm 2$ & $22 \pm 2$ \\
\hline Serum glucose $(\mathrm{mg} / \mathrm{dL})$ & $86 \pm 11$ & $85 \pm 9$ & $86 \pm 10$ \\
\hline Serum total cholesterol $(\mathrm{mg} / \mathrm{dL})$ & $174 \pm 35$ & $165 \pm 27$ & $170 \pm 32$ \\
\hline $\begin{array}{l}\text { Serum low-density lipoprotein } \\
(\mathrm{mg} / \mathrm{dL})\end{array}$ & $103 \pm 30$ & $100 \pm 25$ & $101 \pm 27$ \\
\hline $\begin{array}{l}\text { Serum high-density lipoprotein } \\
(\mathrm{mg} / \mathrm{dL})\end{array}$ & $55 \pm 11$ & $48 \pm 11$ & $51 \pm 12$ \\
\hline Serum triglycerides $(\mathrm{mg} / \mathrm{dL})$ & $84 \pm 49$ & $92 \pm 44$ & $87 \pm 47$ \\
\hline $\begin{array}{l}\text { Family history of cardiovascular } \\
\text { diseases, } \mathrm{n}(\%)\end{array}$ & $10(20 \%)$ & $17(\sim 35 \%)$ & $\begin{array}{l}27 \\
(\sim 27 \%)\end{array}$ \\
\hline
\end{tabular}

Values are given as the mean $\pm \mathrm{SD}$ or as percentage in the sample.

\section{Laboratory stressor tests}

As summarized in Figure 1, all the challenges produced a significant $(\mathrm{p}<0.05)$ increases in systolic and diastolic BP, with the greatest increase being observed with the cold pressor test, followed by the Stroop test and isometric handgrip test. Both psychological and physical stressors caused significant tachycardia.

Figure 1 (left panel) summarizes the changes in systolic and diastolic BP and HR during the handgrip test. This test caused a significant increase in both systolic $\left[F(2,96)=152.85, p<0.001, \eta^{2}=0.614\right]$ and diastolic $\left[F(2,96)=71.49, p<0.001, \eta^{2}=0.427\right] B P$, and this increase was greater in males than in females $\left[F(1,96)=48.30, p<0.001, \eta^{2}=0.335\right]$. The test also caused tachycardia, but without significant differences between males and females $[F(1,96)=4.35, p<0.054$, $\left.\eta^{2}=0.043\right]$. There were no significant differences observed in the recovery time between males and females.
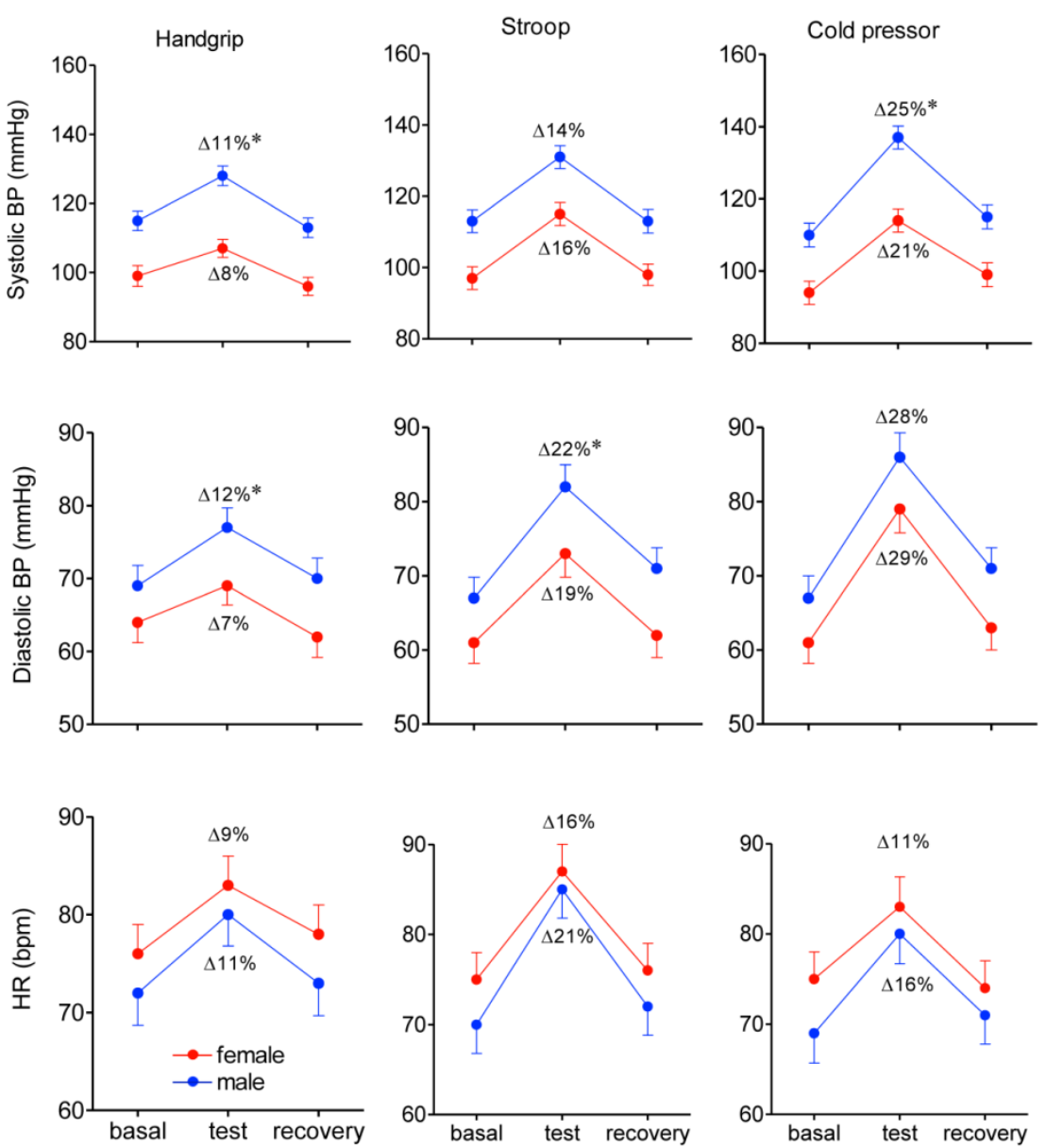

Figure I. Changes in systolic and diastolic blood pressure (BP) and in heart rate (HR) during the handgrip test (at the 3 rd min) Stroop test (at the $4^{\text {th }} \mathrm{min}$ ) and cold pressor test (at the $2^{\text {nd }} \mathrm{min}$ ), comparing males and females. The values are means \pm SEM. Numbers in parenthesis are the relative changes induced by the stressor test. $* p<0.05$ indicates significant difference between males and females. 
The results of the word-color conflict (Stroop) test are shown in Figure 1 (middle panel). We observed a significant increase in systolic BP $\left[F(2,96)=193.75, p<0.001, \eta^{2}=0.669\right]$, which showed a similar magnitude in males (from $113 \pm 3.20$ to $131 \pm 3.20$ $\mathrm{mmHg})$ and females $(97 \pm 3.2$ to $115 \pm 3.2 \mathrm{mmHg})$ $\left[F(1,96)=66.18, p<0.001, \eta^{2}=0.408\right]$. The increase in diastolic BP was significantly higher in males (from $67 \pm 2.8$ to $82 \pm 3.0 \mathrm{mmHg}$ ) than in females (from $61 \pm 2.8$ to $73 \pm 3.2 \mathrm{mmHg}$ ) $\left[F(1,96)=19.54, p<0.001, \eta^{2}=0.169\right]$. A significant stress-induced increase in HR was observed during this test $[F(2,96)=158.07, p<0.001$, $\left.\eta^{2}=0.622\right]$, and there was no difference between males (from $70 \pm 3.2$ to $85 \pm 3.2 \mathrm{bpm}$ ) and females (from $75 \pm 3.0$ to $87 \pm 3.3 \mathrm{bpm})\left[F(1,96)=3.84, p<0.053, \eta^{2}=0.039\right]$. BP and HR decreased during the post-test period to similar levels as baseline in both genders.

Figure 1 (right panel) summarizes the positive chronotropic and pressor responses to the cold pressor test. Systolic BP increased significantly during the test $\left[F(2,96)=298.35, p<0.001, \eta^{2}=0.757\right]$ and it was significantly higher in males (from $110 \pm 3.3$ to $137 \pm 3.2$ $\mathrm{mmHg}$ ) compared with females (from $94 \pm 3.2$ to $114 \pm 3.2 \mathrm{mmHg}$ ) $\left[F(1,96)=112.33, p<0.001, \eta^{2}=0.539\right]$. Diastolic BP also showed a significant increase $\left[F(2,96)=181.30, p<0.001, \eta^{2}=0.654\right]$, but without significant differences between males (from $67 \pm 3.0$ to $86 \pm 3.3 \mathrm{mmHg}$ ) and females (from $61 \pm 2.8$ to $79 \pm 3.2$ $\mathrm{mmHg})\left[F(1,96)=4.21, p<0.056, \eta^{2}=0.008\right]$. HR increased similarly in males (from $69 \pm 3.3$ to $80 \pm 3.3 \mathrm{bpm}$ ) and females $(75 \pm 3.0$ to $83 \pm 3.3 \mathrm{bpm})[F(1,96)=4.55$, $\left.p<0.355, \eta^{2}=0.045\right]$. The hemodynamic values were similarly recovered post-test in both genders.

\section{Classification of hemodynamic responsiveness to laboratory stressors}

As summarized in Figure 2 (top panel), the percent changes in systolic BP due to the stressor were significantly different between the handgrip, Stroop and cold pressor tests (median: 10, 15 and $28 \mathrm{mmHg}$, respectively). Similar results were observed for diastolic BP changes (median: 6, 9 and $18 \mathrm{mmHg}$, respectively), but not for HR changes, for which a significantly higher median was observed for the Stroop test (13 bmp) compared the handgrip test $(6 \mathrm{bpm})$ and the cold pressor test $(8 \mathrm{bpm})$. We also noted that the magnitude of the BP and HR responses were variable between participants; therefore, we classified each individual as pressor and chronotropic hyperreactive based on the $75^{\text {th }}$ percentile for each of the three tests. As shown in Figure 2, the values of systolic BP and diastolic BP were less dispersed in the handgrip test and markedly dispersed in the cold pressor test. The hyperreactivity cutoff for systolic BP was 14, 24 and 36
$\mathrm{mmHg}$, respectively, for the handgrip, Stroop and cold pressor test. The hyperreactivity cutoff for diastolic BP was 9, 13 and $24 \mathrm{mmHg}$, respectively). With regard to HR, participants responded to the tests with variations from 0 to $39 \mathrm{bpm}$ during the isometric handgrip test, 0 to $40 \mathrm{bpm}$ during the Stroop mental test and -14 to $+47 \mathrm{bpm}$ during the cold pressor test. The $75^{\text {th }}$ percentile of this parameter in the handgrip, Stroop and cold pressor tests were 10,17 and $17 \mathrm{bpm}$, respectively.
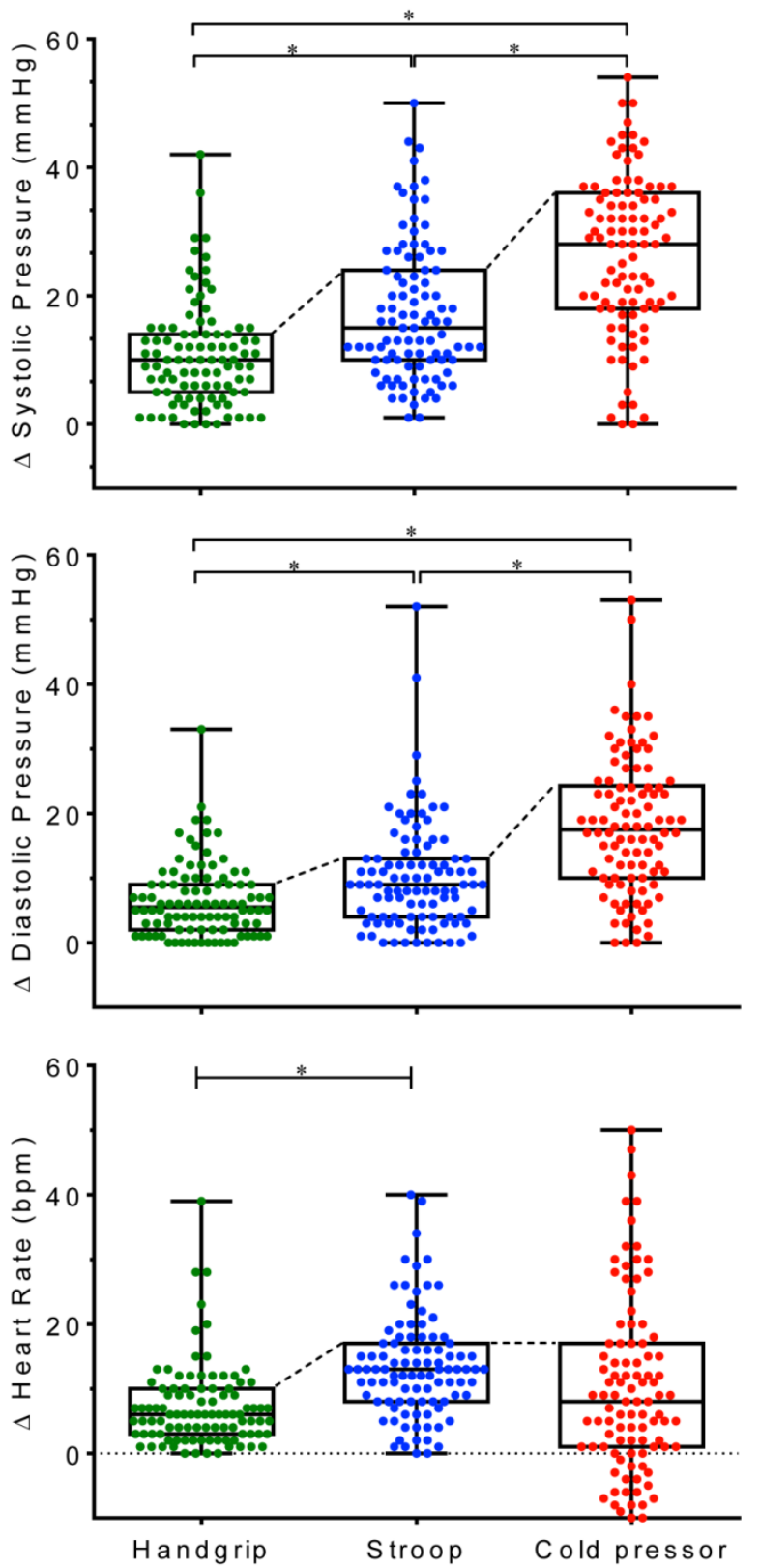

Figure 2. Distribution of absolute pressor and chronotropic responses to each stressor test. Horizontal line in the middle of the box represents the median and the superior horizontal line of the box represents the 75 th percentile. ${ }^{*}<<0.5$ between groups. 
Gender
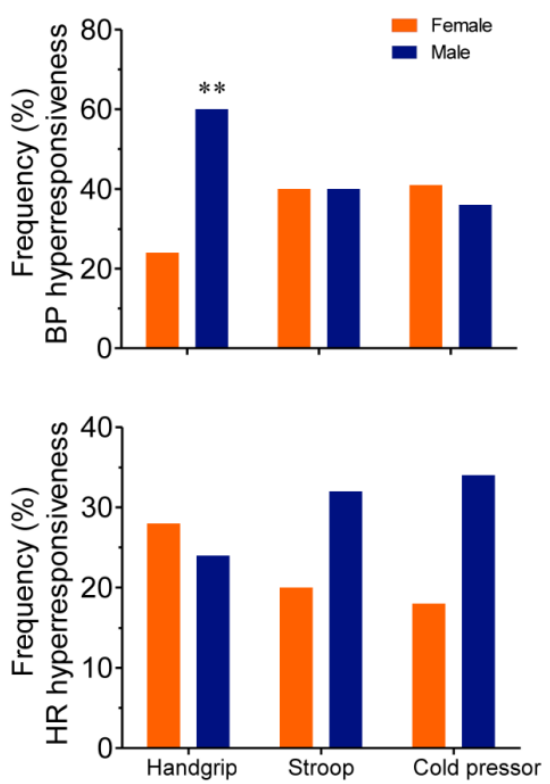

Family History CVD
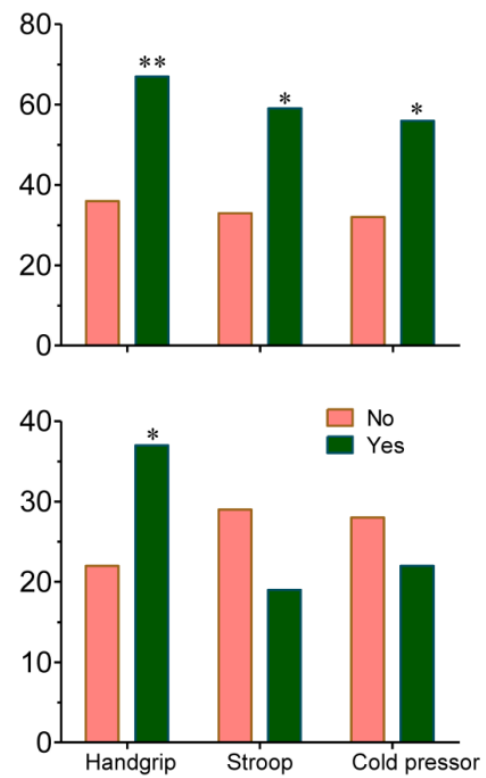

Figure 3. The influence of gender and family history of cardiovascular diseases (CVDs) on the frequency of subjects with pressor (BP) and chronotropic (HR) hyperresponsiveness to stressor tests. The data in the left graphs are from 30 males and 12 females exhibiting hemodynamic hyperresponsiveness. The data in the right graphs are from 26 subjects exhibiting concurrent hemodynamic hyperresponsiveness and a family history of CVDs and from 18 subjects with hemodynamic hyperresponsiveness only. ${ }^{*} p<0.05$ and $* * p<0.01$ compared with female group or with no family history of CVDs group.

\section{Hemodynamic hyperresponsiveness and gen- der}

Figure 3 (left bar graph) shows the proportion of males and females among individuals exhibiting pressor and chronotropic hyperresponsiveness to stressor tests, based on the cutoffs described above. Our data showed that the frequency of participants classified with blood pressure hyperreactivity during the isometric handgrip test was significantly higher for males compared with females (63 vs. $24 \%$, p<0.01). The frequency of participants classified with blood pressure hyperreactivity during the cold pressor and mental tests was similar among males and females. No significant differences were observed in the proportion of males and females with chronotropic hyperresponsiveness during all the stressor tests.

\section{Hemodynamic hyperresponsiveness and fam- ily history of cardiovascular disease}

In our sample of healthy participants, $27 \%$ reported family history of cardiovascular disease. As summarized in Figure 3 (right bar graphs), the frequency of participants classified with BP (systolic and/or diastolic) and chronotropic hyperreactivity during the isometric handgrip test was higher in participants with family history of cardiovascular diseases (67 vs. 36\%, p<0.01) (Figure 3, right bottom graph). None of those individuals who did not re- spond with increase in cardiovascular parameters to the isometric handgrip $(n=11)$, Stroop $(n=9)$ or cold pressor $(n=22)$ tests, which were classified as non-responders, had reported family history of cardiovascular disease. When we used the $25^{\text {th }}$ percentile as a cutoff criterion to determine those who were hyporesponders to the handgrip (n: 20 females and11 males), Stroop (n: 18 females and 14 males) and cold pressor (n: 15 females and 14 males) tests, we observed that only $6(\sim 6 \%)$ had reported family history of cardiovascular disease.

\section{Discussion}

Our study of 98 healthy participants, demonstrates that the cold pressor test elicited higher increases in BP, whereas the Stroop test elicited larger increases in HR. Our data suggest that males exhibited higher increases in BP than females in all stressor tests, and were more likely to exhibit pressor hyperreactivity during the handgrip test. A point of relevance in this study was the relationship between family history of cardiovascular disease and pressor hyperreactivity to stressor tests.

Regarding the values of hyperreactivity studies in the literature the cutoff is based on the ergometric test [30] or comparing two groups and classifying the group exhibiting higher hemodynamic responses as hyperreactive [2]. Ginty et al, [15] classified the indi- 
viduals as exaggerated or blunted reactors on the basis of being at least 2 standard deviations above or below the means of their respective HR means. In the present study we proposed to classify the subjects as exaggerated reactors based on the $75^{\text {th }}$ percentile of the sample as hemodynamic hyperreactives.

Pressor and tachycardic responses to stressors occur in most individuals, and they are dependent on the stressful situation, and how reactive the person is to that situation even when he/she is healthy [31]. Although laboratory stressors are different from stress in real life, they are recognized as important tools to measure cardiovascular reactivity [32]. In the present study, the individuals were subjected to a set of diverse stressors that have mostly been used to examine the influence of cardiovascular hyperresponsiveness on the etiology of cardiovascular disease [1-3,6,8,11]. Individual differences in the cardiovascular response to stress play a central role in the reactivity hypothesis linking frequent exposure to psychosocial stress to adverse outcomes in cardiovascular health $[33,34]$.

We measured both the systolic and diastolic components of BP because systolic pressure is mainly determined by left ventricular ejection and arterial compliance, whereas diastolic pressure is mainly determined by vascular resistance. However, we observed that the relative increase in systolic BP closely followed the relative increase in diastolic BP, which means that the pressor response to each of the stressors involved determinants of both the systolic and diastolic components. In the present study, the BP and HR measurements and the stress tests were applied at a fixed time in the morning (08:00-10:00 h). Using a fixed time rather than a random time was, important because Shea et al. [35] recently evaluated the circadian rhythm of BP in health subjects and observed that the timing of the endogenous circadian peak in $\mathrm{BP}$ occurs in the evening, whereas the lowest circadian BP occurs early in the morning. This change was unrelated to the circadian rhythms in cortisol, catecholamines and the neural control of HR.

It has been demonstrated that physically undemanding active coping tasks generate a cardiac reaction pattern whereas passive coping tasks have been shown to generate vascular response patterns [36,37], which are sympathetic response modes [38]. In healthy persons, we observed that among the three stressors the isometric handgrip caused the smallest variance in the values of $\mathrm{BP}$ and $\mathrm{HR}$ response (see Figure 2, box-whisker graph). Willemsen et al. [39] and Ring et al. [40] found in healthy young individuals that the mental task elicited increases in BP and $\mathrm{HR}$ and that, in contrast, the cold pressor test elicited increases in diastolic BP and no changes or decreases in HR. Interestingly, Ring et al. [16] studied the effects of prolonged mental stress in healthy men and women and observed that the pressor response was initially maintained mainly by cardiac mechanisms and subsequently the predominantly vascular mechanisms. In the present study, although using a different protocol, we observed that the Stroop test elicited increases in both BP and HR and that the cold pressor elicited higher increases in diastolic BP and it was the only test that elicited bradycardia in several individuals (Figure 2).

Comparing the stressor tests we noted in healthy subjects that the passive cold pressor test elicited higher increases in $\mathrm{BP}\left(\sim 30 \mathrm{mmHg}\right.$, at the $\left.2^{\text {nd }} \mathrm{min}\right)$ and the physical handgrip elicited lower increases in BP $\left(\sim 10 \mathrm{mmHg}\right.$, at the $\left.3^{\text {rd }} \mathrm{min}\right)$. An intermediary value was observed with the active mental Stroop test $(\sim 18$ $\mathrm{mmHg}$, at the $\left.4^{\text {th }} \mathrm{min}\right)$; similar results were observed in relation to the chronotropic response. Although the cold pressor test has been considered a bizarre stressor and psychologically and physiologically complex [31], it was important in our study in terms of comparison with the other two stressors and because the pressor and tachycardic responses are greatly determined or at least accompanied by painful cutaneous sensation $[1,41,42]$. Again, it was important that we did not apply this test at a random time given the evidence for the existence of an endogenous circadian periodicity underlying the sensitivity of cortisol to the acute cold pressor test [43]. Considering that small variations in water temperature have significant effects on pain intensity and tolerance time [44, 45], the cold pressor test in the present study was applied under technical conditions to ensure a precise constant temperature of the water in every trial to obtain comparable and reliable results.

Given the lack of cutoff values indicative of hyperreactivity, we proposed adopting a cutoff based on the $75^{\text {th }}$ percentile of the average BP and HR in the sample, which we consider rigorous because the cutoff values were much higher than the average increase in values of systolic and diastolic BP and HR. Recently, Ginty et al. [15] reported that differences between exaggerated and blunted reactors to stress tasks may involve the amygdala and the posterior cingulate systems of the brain. Those investigators have also observed that there were no significant differences between exaggerated and blunted reactors in how difficult, stressful, or engaging they found the task or in their subjective assessment of their performance of the task. In the present study, we observed that, in contrast with the hyperresponders, none of the non-responders and only 6 hyporesponders (using a cutoff based on the $25^{\text {th }}$ percentile) had reported fam- 
ily history of cardiovascular disease. Therefore, studies such as that done by the above investigators are very important to the understanding the functional differences among exaggerated responders, hyporesponders and blunted reactors to stress tasks and the association with vulnerability to and protection against cardiovascular disease risk.

We noted that among subjects with cardiovascular hyperreactivity to stress, the proportion of females was significantly lower than males (24 vs. 63\%) during the isometric handgrip stressor. Gender differences in cardiovascular reactivity to stress are expected due to the protective effects exerted by estrogens, which usually results in reduced signs of cardiovascular disease risk in premenopausal women, compared to men [45]. We observed that fertile females showed lower increases in BP due to the three stressors. This finding is corroborated by prior studies that showed that women exhibited attenuated BP responses during a static handgrip test $[46,47]$ and the cold pressor test [47]. On the other hand, when we considered the individuals classified as hyporesponders, the proportion of females was greater than of males. There is experimental evidence that gender differences in the responses to stressors might be mediated by the sympathetic nervous system. For example, Shoemaker et al. [48] found that males exhibited greater muscle sympathetic nerve activity and greater increases in BP during the postural stress than females. Rozanski et al. [32] also showed that the concurrent increase in sympathetic activity was smaller in females than males. These findings highlight the role played by the autonomic nervous system in the gender-specific hemodynamic responses to stressors.

The highly influential cardiovascular reactivity hypothesis states that individuals showing exaggerated cardiovascular reactivity to stress are at higher risk of developing cardiovascular disease [4, 33,49]. Family history of cardiovascular diseases and cardiovascular reactivity to stressors in healthy young adults have been shown to have some predictive value regarding the risk of developing cardiovascular disease $[19,29,30]$. In agreement with this hypothesis, we observed in our study that most of those individuals who had reported family history of cardiovascular disease were hyperresponders to the stressor tests and the opposite was observed when we analyzed the individuals classified as hyporesponders. Increased sympathetic activity is considered the main underlying mechanism of the development of hypertension in young subjects with a positive family history of cardiovascular disease $[19,30]$. We speculate that vasodilator endothelial dysfunction induced by reduced nitric oxide release and exacerbated central and/or peripheral sympathetic activity on the heart and resistance vessels are possible mechanisms involved in the hyperactivity to stressor tests in individuals with family history of cardiovascular disease. Although our finding of a positive relationship between family history of cardiovascular disease and pressor hyperreactivity to stressor tests may contribute to the understanding of the relation between hemodynamic hyperreactivity to sympathoexcitatory stimuli and future incidences of cardiovascular diseases, further progress in genetic association studies might help to uncover the molecular pathways leading from genes to stress reactivity. Moreover, future studies should evaluate the role played by the neuroreflex mechanisms of cardiovascular function regulation, which plays a pivotal role in buffering oscillations in BP and HR under resting conditions [50] and during the laboratory stressor tests in hemodynamic normoreactive and hyperreactive subjects.

\section{Conclusion and limitations}

In summary, we have shown that the cold pressor test elicited higher increases in BP and that mental stress elicited larger increases in HR. Moreover, we observed that males exhibited higher increases in BP in all stressor tests and that males and participants with family history of cardiovascular disease were more likely to exhibit hemodynamic hyperreactivity based on our proposed hyperreactive criteria. A limitation of the present study is that it was not taken from the participants a self report of how stressful they found each test or how engaged they were in the tasks.

\section{Acknowledgments:}

The authors gratefully acknowledge Dr. Fernando Pretti and laboratory Bioclinico for the biochemical analyzes. ECV and SSM are supported by the National Council for the Development of Science and Technology (CNPq) and the State Agency for the Development of Science and Technology (FAPES).

\section{Competing Interests}

FHSK became a full time employee for Philips Respironics (USA) after the collection of the data provided in this article.

\section{References}

1. Hines JrEA, Brown GE. The cold pressor test for measuring the reactibility of the blood pressure: Data concerning 571 normal and hypertensive subjects. Am Heart J. 1936; 11: 1-9. doi:10.1016/S0002-8703(36)90370-8

2. Herkenhoff F, Lima EG, Mill JG. Arterial pressure reactivity to experimental stress tests in normotensive humans with arterial pressure hyperreactivity during submaximal exercise. Braz J Med Biol Res. 1994; 27(6): 1425-30. 
3. Lima EG, Spritzer N, Herkenhoff FL, et al. Noninvasive ambulatory 24-hour blood pressure in patients with high normal blood pressure and exaggerated systolic pressure response to exercise. Hypertension 1995; 26: 1121-1124. doi:10.1161/01.HYP.26.6.1121

4. Carroll D, Ginty AT, Der G, et al. Increased blood pressure reactions to acute mental stress are associated with 16-year cardiovascular disease mortality. Psychophysiology.
2012;
49(10):1444-1448.
doi: 10.1111/j.1469-8986.2012.01463.x

5. Stroop JR. Studies on inference in serial verbal reaction. J Exp Psychol. 1935; 18: 643-62. doi:10.1037/h0054651

6. Yeung AC, Vekshtein VI, Krantz DS, et al. The effect of atherosclerosis on the vasomotor response of coronary arteries to mental stress. N Engl J Med. 1991; 325(22): 1551-6. doi:10.1056/NEJM199111283252205

7. Loures DL, Sant Anna I, Baldotto CS, et al. Mental stress and cardiovascular system. Arq Bras Cardiol. 2002; 78(5): 525-30.

8. Alam M, Smirk FH. Observations in man upon a blood pressure raising reflex arising from the voluntary muscles. J Physiol. 1937; 89(4): 372-83.

9. Trombetta IC, Batalha LT, Rondon MU, et al. Gly16 + Glu27 beta2-adrenoceptor polymorphisms cause increased forearm blood flow responses to mental stress and handgrip in humans. J Appl Physiol. 2005; 98(3): 787-94. doi: 10.1152/japplphysiol.00503.

10. Aboussafy D, Campbell TS, Lavoie K, et al. Airflow and autonomic responses to stress and relaxation in asthma: the impact of stressor type. Int J Psychophysiol. 2005; 57(3): 195-201. doi:10.1016/j.ijpsycho.2005.02.004

11. Kuniyoshi FH, Trombetta IC, Batalha LT, et al. Abnormal neurovascular control during sympathoexcitation in obesity. Obes Res. 2003; 11(11): 1411-9. doi:10.1038/oby.2003.190

12. McAdoo WG, Weinberger $\mathrm{MH}$, Miller $\mathrm{JZ}$, et al. Race and gender influence hemodynamic responses to psychological and physical stimuli. J Hypertens. 1990; 8(10): 961-7. doi:10.1097/00004872-199010000-00012

13. Richter CM, Panigas TF, Bündchen DC, et al. Blood pressure reduction in hyper-reactive individuals after aerobic exercise. Arq Bras Cardiol. 2010; 95(2): 251-7. doi: 10.1590/S0066-782X2010005000085

14. Wright CE, O'Donnell $\mathrm{K}$, Brydon L, et al. Family history of cardiovascular disease is associated with cardiovascular responses to stress in healthy young men and women. Int J Psychophysiol. 2007; 63(3):275-282. doi: 10.1016/j.ijpsycho.2006.11.005

15. Ginty AT, Gianaros PJ, Derbyshire SW, et al. Blunted cardiac stress reactivity relates to neural hypoactivation. Psychophysiology. 2013; 50(3):219-229. doi: 10.1111 /psyp.12017.

16. Ring C, Burns VE, Carroll D. Shifting hemodynamics of blood pressure control during prolonged mental stress. Psychophysiology. 2002; 39(5):585-590.

17. Everson SA, Lynch JW, Chesney MA, et al. Interaction of workplace demands and cardiovascular reactivity in progression of carotid atherosclerosis: population based study. BMJ. 1997;314(7080):553-558. doi: 10.1136/bmj.314.7080.553.

18. Parker FC, Croft JB, Cresanta JL, et al. The association between cardiovascular response tasks and future blood pressure levels in children: Bogalusa Heart Study. Am Heart J. 1987; 113(5): 1174-9. doi:10.1016/0002-8703(87)90931-8

19. Lopes HF, Bortolotto LA, Szlejf $C$, et al. Hemodynamic and metabolic profile in offspring of malignant hypertensive parents. Hypertension 2001; 38(3 Pt 2): 616-20. doi:10.1161/hy09t1.094504

20. Everson SA, Kaplan GA, Goldberg DE, et al. Anticipatory blood pressure response to exercise predicts future high blood pressure in middle-aged men. Hypertension. 1996;27(5):1059-1064. doi: 10.1161/01.HYP.27.5.1059.

21. Matthews KA, Woodall KL, Allen MT. Cardiovascular reactivity to stress predicts future blood pressure status. Hypertension. 1993; 22(4): 479-485. doi:10.1161/01.HYP.22.4.479.

22. Matthews KA, Owens JF, Kuller LH, et al. Stress-induced pulse pressure change predicts women's carotid atherosclerosis. Stroke. 1998; 29(8):1525-530. doi:10.1161/01.STR.29.8.1525.

23. Kapuku GK, Treiber FA, Davis HC, et al. Hemodynamic function at rest, during acute stress, and in the field: predictors of cardiac structure and function 2 years later in youth. Hypertension. 1999; 34(5):1026-2031. doi: 10.1161/01.HYP.34.5.1026.

24. Carroll D, Ring C, Hunt K, et al. Blood pressure reactions to stress and the prediction of future blood pressure: effects of sex, age, and socioeconomic position. Psychosom Med. 2003; 65(6):1058-1064. doi: 10.1097/ 01.PSY.0000097330.58739.26.

25. Manuck SB, Polefrone JM, Terrell DF, et al. Absence of enhanced sympathoadrenal activity and behaviorally evoked cardiovascular reactivity among offspring of hypertensives. Am J Hypertens. 1996;9(3):248-255

26. Fredrikson M, Matthews KA. Cardiovascular responses to behavioral stress and hypertension: A meta-analytic review. Ann Behav Med. 1990; 12(1):30-39.

27. Chida Y, Steptoe A. Greater cardiovascular responses to laboratory mental stress are associated with poor subsequent cardiovascular risk status: a meta-analysis of prospective evidence. Hypertension. 2010;55(4):1026-1032. doi:10.1161/HYPERTENSIONAHA.109.146621.

28. Thayer JF, Ahs F, Fredrikson M, et al. A meta-analysis of heart rate variability and neuroimaging studies: implications for heart rate variability as a marker of stress and health. Neurosci Biobehav Rev. 2012;36(2):747-56. doi: 10.1016/j.neubiorev.2011.11.009.
29. Faul F, Erdfelder E, Lang AG, et al. G*Power 3: a flexible statistical power analysis program for the social, behavioral, and biomedical sciences. Behav Res Methods 2007; 39(2): 175-91. doi:10.1186/1471-2350-9-81

30. Williams RR, Hunt SC, Hopkins PN, et al. Familial dyslipidemic hypertension. Evidence from $58 \mathrm{Utah}$ families for a syndrome present in approximately $12 \%$ of patients with essential hypertension. JAMA 1988; 259(24): 3579-86. doi: 10.1001/jama.259.24.3579.

31. Zanstra YJ, Johnston DW. Cardiovascular reactivity in real life settings: measurement, mechanisms and meaning. Biol Psychol. 2011; 86(2): 98-105. doi:10.1016/j.biopsycho.2010.05.002

32. Rozanski A, Blumenthal JA, Kaplan J. Impact of psychological factors on the pathogenesis of cardiovascular disease and implications for therapy. Circulation 1999; 99(16): 2192-7. doi:10.1161/01.CIR.99.16.2192

33. Treiber FA, Kamarck T, Schneiderman N, et al. Cardiovascular reactivity and development of preclinical and clinical disease states. Psychosom Med. 2003; 65(1): 46-62.

34. Kamarck TW, Lovallo WR. Cardiovascular reactivity to psychological challenge: conceptual and measurement considerations. Psychosom Med. 2003; 65(1): 9-21._doi:10.1097/01.PSY.0000030390.34416.3E

35. Shea SA, Hilton MF, Hu K, et al. Scheer FA. Existence of an endogenous circadian blood pressure rhythm in humans that peaks in the evening. Circ Res. 2011; 108(8): 980-84. doi: 10.1161/CIRCRESAHA.110.233668.

36. Light $\mathrm{KC}$, Obrist PA. Cardiovascular reactivity to behavioral stress in young males with and without marginally elevated casual systolic pressures. Comparison of clinic, home, and laboratory measures. Hypertension 1980; 2(6): $802-8$.

37. Tomaka J, Blascovich J, Kibler J, et al. Cognitive and physiological antecedents of threat and challenge appraisal. J Pers Soc Psychol. 1997; 73(1): 63-72.

38. Donadio V, Karlsson T, Elam M, et al. Interindividual differences in sympathetic and effector responses to arousal in humans. J Physiol. 2002; 544(Pt 1): 293-302. doi:10.1113/jphysiol.2002.020099.

39. Willemsen G, Ring C, Carroll D, et al. Secretory immunoglobulin A and cardiovascular reactions to mental arithmetic and cold pressor. Psychophysiology. 1998; 35(3):252-259.

40. Ring C, Harrison LK, Winzer A, et al. Secretory immunoglobulin A and cardiovascular reactions to mental arithmetic, cold pressor, and exercise: effects of alpha-adrenergic blockade. Psychophysiology. 2000;37(5):634-643. doi: 10.1111/1469-8986.3750634.

41. Kregel KC, Seals DR, Callister R. Sympathetic nervous system activity during skin cooling in humans: relationship to stimulus intensity and pain sensation. J Physiol. 1992; 454: 359-71.

42. Wolf S, Hardy JD. Studies on pain: observations on pain due to local cooling and on factors involved in the "cold pressor" effect. J Clin Invest. 1941; 20(5): 521-33. doi:10.1172/JCI101245

43. van Eekelen AP, Kerkhof GA, van Amsterdam JG. Circadian variation in cortisol reactivity to an acute stressor. Chronobiol Int. 2003; 20(5): 863-78.

44. Mitchell LA, MacDonald RA, Brodie EE. Temperature and the cold pressor test. J Pain. 2004; 5(4):233-7. doi:10.1016/i.jpain.2004.03.004.

45. Novella S, Dantas AP, Segarra G, et al. Vascular aging in women: is estrogen the fountain of youth? Front Physiol. 2012; 3: 165. doi:10.3389/fphys.2012.00165

46. Ettinger SM, Silber DH, Collins BG, et al. Influences of gender on sympathetic nerve responses to static exercise. J Appl Physiol. 1996; 80(1): 245-51.

47. Jarvis SS, VanGundy TB, Galbreath MM, et al. Sex differences in the modulation of vasomotor sympathetic outflow during static handgrip exercise in healthy young humans. Am J Physiol Regul Integr Comp Physiol. 2011; 301(1): R193-200. doi:10.1152/ajpregu.00562.2010

48. Shoemaker JK, Hogeman CS, Khan M, et al. Gender affects sympathetic and hemodynamic response to postural stress. Am J Physiol Heart Circ Physiol. 2001; 281(5):H2028-35.

49. Krantz DS, Manuck SB. Acute psychophysiologic reactivity and risk of cardiovascular disease: a review and methodologic critique. Psychol Bull. 1984; 96(3): 435-64.

50. Vasquez EC, Meyrelles SS, Mauad H, et al. Neural reflex regulation of arterial pressure in pathophysiological conditions: interplay among the baroreflex, the cardiopulmonary reflex and the chemoreflex. Braz J Med Biol Res. 1997; 30(4): 521-32. 